\title{
Comparative Research on Chinese Logistics Models of Cross-Border E-Commerce
}

\author{
Yufen Wang ${ }^{1, a^{*}, \text { Min Zhao }}{ }^{2, b}$ \\ ${ }^{1}$ School of Economics and Management, Nanjing University of Traditional Chinese Medicine, \\ Nanjing, Jiangsu, China \\ ${ }^{2}$ School of Business, Hohai University, Nanjing, Jiangsu, China \\ a wangyufen0168@sina.com, ${ }^{\mathrm{b}}$ zhaomin3451@sina.com
}

\begin{abstract}
Keywords: Cross-border e-commerce, Logistics model, Advantage, Disadvantage
Abstract. Chinese cross-border e-commerce has been developing rapidly in recent years, while logistics is a weak link in the process of cross-border e-commerce. There are three main logistics models in cross-border e-commerce: third party logistics, overseas warehousing and logistics alliance. The advantages and disadvantages of the three models are respectively analyzed. Based on the analysis the authors put forward suggestions on logistics model selection for enterprises and on developing cross-border e-commerce logistics for the government.
\end{abstract}

\section{Introduction}

Chinese cross-border e-commerce has expanded rapidly in recent years. The data published by China e-commerce research center show, "The trade value of Chinese cross-border e-commerce was RMB $¥ 1,100$ billion in 2010 , and it rose to RMB $¥ 4,200$ billion in 2014 . Of the total value of 2014 , exports accounted for 85.4 percent, while the proportion of imports was only 14.6 percent. In new normal state, the growth of Chinese foreign trade has slowed down, but cross-border e-commerce maintains high-speed growth and becomes a new motive force to push economy. As to business models, B2B is the majority as same as domestic e-commerce. The proportion of B2B reached 93.5 percent in 2014.

In China, rapidly developing cross-border e-commerce brings huge opportunities to logistics industry, at the same time cross-border logistics is also facing a lot of new challenges. Logistics associated with cross-border e-commerce is a series of service process in order to meet the logistics needs of cross-border e-commerce customers. The services of warehousing, transportation and distribution are provided to carry out goods delivery at the least cost and time. Cross-border e-commerce has changed development environment and competition rules of logistics industry in traditional international trade. It has higher requirements to logistics than usual, but logistics has lagged behind. The research on logistics models of cross-border e-commerce has important significance to promote the development of both cross-border e-commerce and cross-border logistics.

\section{Chinese Main Logistics Models of Cross-border E-commerce}

Unlike traditional international trade logistics, cross-border e-commerce logistics has showed some new features to meet new requirements, such as higher timeliness, small scale, scattered and high frequency. In addition, the main method of traditional international logistics is by sea, while transportation of cross-border e-commerce logistics is diverse. At present, Chinese main logistics models of cross-border e-commerce are as follows: third party logistics, overseas warehousing and logistics alliance.

Third party logistics. Third party logistics is an outsourced provider ("third party") that handles supply chain management for another enterprise. Here it refers to the activity of outsourcing logistics and distribution by cross-border e-commerce enterprises to logistics service providers. Cross-border third party logistics is an inevitable result of specialization in logistics industry. Cross-border e-commerce enterprises outsource logistics to the third party, and the party typically specializes in 
transportation and other logistics services of supply chain to meet customers' demands. So it is a win-win strategic partnership relationship.

Overseas warehousing. Overseas warehousing is the logistics model that sellers of cross-border e-commerce directly establish warehouses for goods storage overseas. Cross-border e-commerce enterprises can store goods in advance in overseas warehouses. Once an order is placed on cross-border e-commerce platform, the seller can deliver and distribute the ordered goods directly from the nearest warehouse to the buyer. Effective operation of overseas warehousing depends on estimation of market size in target country.

Logistics alliance. Logistics alliance is the logistics model between self-operated logistics and outsourcing logistics. It combines the advantages of self-operated logistics and outsourcing logistics and reduces the risks of the two opposite models. Logistics alliance is organized by two or more economic organizations to cooperate through signing contract in the long term. The main purpose is to make use of members' advantages to share resources, have complementary advantages and achieve logistics objective together. It is characterized with interdependence, mutual cooperation, risk and benefit sharing of alliance members.

\section{The advantages and disadvantages of third-party logistics}

\section{The advantages of third-party logistics}

It can meet scattered logistics demand of cross-border e-commerce customers. Due to wide range of cross-border e-commerce, customers are often from all over the world. This requires that cross-border e-commerce enterprises have a powerful delivery and distribution capacity of goods. However, for most of e-commerce enterprise, it is difficult to meet the requirement, while third party logistics can meet the scattered logistics service demands of customers. Third party logistics enterprises gather scattered demands and provide transportation, storage, distribution and other professional services. In addition, they can benefit from scale economy. The cost is lower compared with self-operated logistics of e-commerce enterprises.

It is conducive for cross-border e-commerce enterprises to enhance competitiveness. Third party logistics model is outsourcing logistics for cross-border e-commerce enterprises, so it can save basic investment in logistics for cross-border e-commerce enterprises. E-commerce enterprises can not only save resources, but also reallocate and optimize limited resources on core business. Concentrating on core businesses is conducive to enhance competitiveness.

Social resources can be more effectively used from the whole society. E-commerce is based on internet, so it can easily achieve cross-border transactions. However, difficulty of logistics is highly increased because of cross-border transactions. If there were no third party logistics, every enterprise would build their own logistics system. It would be a great waste of social resources. The third party can integrate social resources and provide global logistics services with more convenience and in less time. It can also obtain the benefits of specialization and scale economy.

\section{The disadvantages of third-party logistics}

E-commerce enterprises have less controllability to the goods. Many cross-border e-commerce enterprises choose third party logistics for the limits of their size and strength, but they are likely to over rely on third party logistics. Cross-border logistics usually takes a long time to transport goods, but e-commerce enterprises usually cannot track the goods in a period because of information asymmetry or some other reasons. To e-commerce enterprises it is hard to control risks in the overall process. Sometimes the quality and scope of logistics service are subjected to the third party.

It is difficult to meet the demand of personalized logistics service. Generally speaking, third party logistics provides professional and standard logistics services. In other words, it is hard to provide services in accordance with diverse requirements of customers. At present, logistics industry is developing very rapidly and customers have higher logistics service requirements than usual, but third party logistics is not suitable to customized logistics services. 


\section{The advantages and disadvantages of overseas warehousing}

\section{The advantages of overseas warehousing}

It can improve logistics service experience of customers. Overseas warehousing is the most effective cross-border logistics model to shorten delivery time. Once an order is placed the goods can be directly delivered from the nearest domestic warehouse. Customers can experience convenient logistics service without delay. Compared with international express delivery overseas warehousing model has fewer limits of goods volume and weight. Customers have more choices on shopping category. In addition, the charge of overseas warehousing is lower than international express. Customers spend less money and enjoy more convenient logistic service, so the service experience of customers is largely improved.

It can upgrade the service level of cross-border e-commerce. The cross-border transportation of overseas warehousing model still uses traditional international logistics. A large number of goods are gathered and shipped to another country. Customs clearance of traditional international trade is adopted. The procedure of bulk goods delivery is more convenient than small-scale and frequent transportation. Since the goods can be delivered to target market in advance, e-commerce enterprises can make immediate response to orders. And e-commerce enterprises can always track the goods online, so riskiness can be controlled effectively. To e-commerce enterprises, this model turns passive waiting for distribution to remote monitoring overall process.

\section{The disadvantages of overseas warehousing}

It is difficult to predict the stocks accurately. Overseas warehousing model is based on the expectations for sales of goods in advance, but it is difficult to predict the size of target market accurately because the market is dynamic. If the goods in stock are much more than sale, overstocked goods tie up capital and cause extra warehouse fee. Poor sales even lead to deliver the stocks back. Conversely, if stocks are less than sale, it results in customer chum and impacts cross-border e-commerce sales. Then the advantages of overseas warehousing will be gone.

It is not suitable to personalized products. Overseas warehousing model needs to store a certain quantity of goods in advance. It is not feasible to customize products according to special requirements of customers. Only standard goods are suitable to overseas warehousing.

\section{The advantages and disadvantages of logistics alliance}

\section{The advantages of logistics alliance}

Logistics alliance members share resources and take complementary advantages. Cross-border e-commerce logistics concerns many complex problems that domestic logistics is not involved. Many enterprises are not capable of accomplishing it with their own strength, so logistics alliance is a reasonable choice. Whether to take part in an alliance or not depends on the judgement that the benefits to join the alliance is greater than to develop respectively. After joining an alliance, the members can share, reallocate and use resources in a wider range. The members can achieve the economic effect of " $1+1>2$ ", otherwise they will quit.

Logistics alliance can provide logistics service of higher quality at lower price. Logistics alliance model is conducive to integrate advantages of alliance members. Compared with separate enterprise before forming alliance, alliance has obvious advantages in the whole process of logistics service. It can reduce cost and improve service quality. Cross-border e-commerce enterprises can usually track logistics information and improve customer satisfaction under this model.

The disadvantages of logistics alliance

Operation efficiency of logistics alliance is uncertain. The reason to join an alliance is the expectation for benefits. If logistics alliance members can't acquire expected benefits or distribution of benefits is unreasonable, negative cooperation among partners may happen. This is likely to weaken complementary advantage of alliance members. In fact, it is common that partners cannot integrate manpower, material resources and financial resources effectively. 


\section{Conclusion}

Table 1 Comparison of Chinese Logistics Models of Cross-Border E-Commerce

\begin{tabular}{|c|c|c|c|}
\hline Item & Third party logistics & Overseas warehousing & Logistics alliance \\
\hline enterprise size & SME & Large & All \\
\hline investment & Small & Large & Medium \\
\hline timeliness & Slow & Fast & Medium \\
\hline Riskiness & Uncontrolled & Controlled & Controlled \\
\hline convenience & Low & High & Medium \\
\hline logistics charge & High & Low & Medium \\
\hline customization & Yes & No & Yes \\
\hline
\end{tabular}

\section{Suggestions to choose logistics model for cross-border e-commerce enterprises}

As shown in Table 1, three logistics models of cross-border e-commerce are compared from seven items, and the results are not all the same. Therefore, it can only be concluded which one is superior in some respect, and no model has absolute advantage. However, according to table 1 we can conclude that overseas warehousing is superior to the other two on most items. It shows overseas warehousing is a promising model to develop in future. For cross-border e-commerce enterprises or individuals, how to choose logistics model depends on different circumstances. Enterprises should make an appropriate choice according to their own condition, environment, business scope, logistics requirement and characteristics of different models.

For example, from the perspective of enterprise size alone, overseas warehousing is the best choice for large and powerful enterprises; third party logistics is an economical and reasonable choice for small and medium enterprises or individuals. Although logistics alliance has no restrictions of enterprise size and strength, formation of an alliance depends on many other factors besides the willingness of enterprises. The above situation will be different if target market is considered. Even if it is a large enterprise, it is not proper to establish overseas warehouse if market capacity is small. And it will be more complex if other factors are taken into consideration. In a word, logistics model selection of cross-border e-commerce is the result of comprehensive consideration of various factors.

\section{Suggestions to develop cross-border e-commerce logistics for the government}

The government should formulate and implement positive industrial policies to encourage the develpment of cross-border e-commerce logistics. The government can support e-commerce enterprises on information, funds, manpower and guide them to establish overseas warehouses or join logistics alliance. Besides policy support, another important function of the government is to develop infrastructure to promote cross-border logistics. Local government can construct ports, wharfs and warehouses, and build qualified city into a transportation hub and distribution center. In the respect of soft environment construction, the government should put emphasis on foreign trade integrated service platform, integrating logistics service to the platform to obtain coordinated development.

\section{Acknowledgement}

This paper is funded by Jiangsu Soft Science Project No. BR2015068 and Nanjing University of Traditional Chinese Medicine Key Discipline Economics and Management of Medicine.

\section{References}

[1] Youwei Lai, Kaiqian Wang, Guangqian Li, The major challenges and policy suggestions of Chinese cross-border e-commerce[N]. The Economic Times, 2014-06-19(05) (In Chinese)

[2] Xiangyang Li, The development path of cross-border e-commerce logistics [J]. China Business and Market, 2014(10):107-112 (In Chinese) 